\title{
Development of On-line Shopping Mart System for Developing Countries
}

\author{
Awoyelu, I.O (Corresponding Author) \& Tangba O \\ Department of Computer Science \& Engineering \\ Obafemi Awolowo University, Ile-Ife, Nigeria \\ E-mail: iawoyelu@oauife.edu.ng \\ Awoyelu F.E \\ Department of Agricultural Economics \\ Federal University of Technology, Akure, Nigeria
}

\begin{abstract}
In Nigeria and most Developing Countries, buying and selling of goods are done in a market. This situation is faced with diverse problems. These problems include the need for buyers and sellers to come into physical contact, the necessary need for potential buyers to visit the shop and non-flexibility in time usage. In order to overcome these problems, an On-line Shopping Mart system (EasyShop) is developed.

This is done by developing an information system database that stores and processes information about buyer's orders, sellers and products. The database is queried to respond to clients' requests. It is updated with clients' requests. The system is a web application designed using ASPX/Microsoft C\# .NET programming language and the database is designed by using MySQL Server.

The proposed system can be used for shopping activities by developing countries. It is an easy to use information system that will assist both buyers and sellers shop effectively.
\end{abstract}

Keywords: On-line shopping, Information system, Database, Buyers, Sellers

\section{Introduction}

In Nigeria and most developing countries, buying and selling of goods are done in a market. The concept of exchange leads to the concept of a market. According to Kotler (1997), exchange is the act of obtaining a desired product from someone by offering something in return. A market consists of all the potential customers sharing a particular need or want who might be willing and able to engage in exchange to satisfy that need or want. (Kotler, 1997). Traditionally, a market is the place where buyers and sellers gathered to exchange their goods, such as a village square. This traditional concept of a market is faced with diverse problems. These problems include:

activities;

The essential need for buyers and sellers to come into physical contact to do their market

$\bullet$ and discomfort;

The necessary need for potential buyers to visit the shop which may take a lot of time, money

- $\quad$ Non-flexibility in time usage.

In order to overcome these problems, On-line Shopping Mart is developed. However, this is practically non-existent in Nigeria and in many Third World Countries. This is because of lack of appropriate computing facilities, insecurity and lack of trust, culture, user resistance and inadequate means of payments via the internet.

The main purpose of this paper is to introduce recharge cards as means of payment to reduce the problem of paying through debit/credit cards, which are not easily accessible to most people. Hence, this paper presents the development of a dynamic, user-friendly system with high security and reliability for Online Shopping in developing countries and in Nigeria in particular. This solution is christened EasyShop. The solution is an E-commerce application that uses the Internet and database technologies. It allows users that are connected to the Internet to search for goods and services, pay via debit recharge cards and have their goods delivered to them.

\section{Online Shopping and Internet}

Shopping is the purchase of goods and services. One version of shopping is called window shopping, which is simply examining the goods without buying them. Shopping is considered a recreational activity of psychological interest. It involves selection, purchase, and display behavior. 
On-line shopping is "a single, homogenous activity, the selling of goods and services via the World Wide Web" (Birkin et al., 2002). Internet's global connectivity can provide organizations with relatively easy access to business or individual customers who would normally be outside their market area.

Businesses can find new ways for selling and promoting their products and services abroad because the Internet facilitates cross-border transactions and information flows (Quelch and Klein, 1996). Especially, for organizations that find the cost of selling/promoting too expensive, Internet is a valuable source that enables the connection of individuals regardless of the location, computer type or operating system provided that they have a World Wide Web (WWW) browser with access to the Internet. Sterne (1995) shows that Web sites providing product information also lower their costs by shortening the sales cycle and reducing the amount of time that sales staff must spend. This means that businesses can achieve higher profits while charging lower prices. Utilizing a "self-service" over Internet costs only \$2.23 per transaction (Row, 1997). This means that goods' transactions can also benefit by using "self-service" over Internet. Customer "self-service" can inspire new innovative approaches to customer service and supports interact with a human customer-support expert. As it has already been mentioned, Internet tools enable the creation of interactive, flexible and customized web applications. Companies can approach their customers effectively by customizing their web-services. Bakos (1998) states that communications and product offerings can be tailored precisely to individual customers. Web pages have capabilities for interacting with viewers that cannot be found in traditional print media (i.e. newspapers).

Using Internets interactive capabilities and providing relevant/customized information, organizations can attract new customers. Also, by enhancing the Web site with chat, message boards and community building features as means of encouraging customers to spend more time, return more frequently, customers are twice as likely to purchase the services and/or products provided (Rafter, 1998). The Web shifts more marketing and selling activities to the customers, as customers fill out their own on-line forms (Hoffman et al, 1995).

Online Shopping represents the automation of traditional paper-based business processes. However, in order to enjoy all the benefits of online business, it requires careful management to address the legal, security and privacy issues. For example, Web site visitors may be unwilling to supply personal information such as name, address, e-mail address because they do not trust the organization and the way it is going to use this information. Furthermore, frequent Internet users are more likely to adopt an online purchasing behavior, therefore the web site needs to be "user friendly" and show a certain security in the transaction process. Birkin et al. (2002) noted that although e-commerce is growing fast, it is also risky in terms of profitability and cash return.

Online shopping is the process consumers go through to purchase products or services over the internet. An online shop, Internet shop, web shop or online store evokes the physical analogy of buying products or services at a bricks-and-mortar retailer or in a shopping mall. It is an electronic commerce application used for business to business (B2B) or business to customer (B2C). As at 2005 Online Shopping has become well-established in major cities across much of North America, Western Europe, and certain East Asian countries like South Korea. However, Online Shopping is still emerging slowly in some industrialized countries, and is practically nonexistent in many Third World countries. Online Shopping has unlimited potential for both developed and developing nations, offering lucrative profits in a highly unregulated environment.

Online shoppers commonly use their Credit card for making payments, however some systems enable users to create accounts and pay by alternative means, such as Debit card, Credit card, all kinds of Electronic money, Ecash (or digital money), Cash on delivery (C.O.D.), ChequeMoney transfer / delivery on payment, Postal money order. Once a payment has been accepted the goods or services can either be downloaded from the internet or delivered to the consumer via traditional means.

However, these media of payment are not easily accessible, especially to the rural dwellers. Today in Nigeria, hundreds of thousands of people are getting the internet access from their WAP-enabled mobile phones, smart phones and from their PCs using their phones as a modem, reflect the importance and necessity of internet connectivity in the country. This is mainly due to the introduction of General Packet Radio service (or GPRS) connectivity by the GSM operators (Ayny, 2009).

There have been some existing web sites for on-line shopping such as Amazo.com and eBay.com. These existing on-line shopping systems have limitations. They are designed for use in developed countries and for learned individuals. The grass root people do not have access to debit/credit cards, which are the only means of buying and selling on the net. Hence, the proposed system addresses the issue of buying and selling by the use of recharge cards as in the case of mobile communications. 


\section{Proposed Model}

Unified Modeling Language (UML) is used for the design of the proposed system. This involved the use of Use case, class diagram and state chart diagram.

The Use Case model of the system is as shown in Figure 1. The actors are the sellers, buyers and delivery agent.

A buyer is considered to be the person that actually performs a search for a commodity after registration. The seller registers and fills out the form to sell items. The delivery agent registers for an account to deliver goods category and the bank authorizes the purchase of goods.

Based on the Use Case Model, the following requirements are identified:

1) The Online Shopping Mart (EasyShop) Website searches properties to buy.

2) The Online Shopping Mart Website displays full goods details information.

3) EasyShop includes recharging account and payment abilities.

4) EasyShop displays customers account balance on request.

5) The EasyShop includes customers, suppliers and delivery agent registration, which will include name, contact address, password and other important information.

6) The EasyShop Website has customer care information.

7) A Supplier supplies goods and define its details and description.

8) Order for products: a registered customer adds products to the shopping cart. After supplying user id and password and this order can be deleted.

9) The delivery agent and seller receive information on order via email.

The figure shows a possible Use Case Model based on the research finding. The model suggests that there are three actors. Table 1 gives the use case specification of ordered goods.

The classes involved in the system, as shown in the class diagram in Figure 2, include buyer, seller, product, order, payment, and account. The class diagram is based on the use case model and the use case specification. The following presents the assumptions of the system.

1) Buyer class represents the list of buyer registered to use the system.

2) Seller class represents the list of suppliers registered to use the site.

3) Products class represents the list of products being supplied by the sellers.

4) Order class represents the list of orders made by customers.

5) Payment represents the payment of goods order for by the buyer.

6) Account class represents recharging of account by buyers.

\subsection{System Design}

This involves the transformation of the class diagram analysis into the design class diagram.

\subsubsection{Design Class Diagram}

The process of designing the class diagram involves the production of a diagram whose specifications have been completed to such a degree that it can be implemented. Based on the analysis diagrams which address "what" a system should do, the design class is about "how" the requirement will be implemented based on the chosen programming language. Figure 3 shows the design class diagram for the system.

The design class diagram shows the classes that make up the whole application. It shows that many aggregation relationships exist demonstrating the fact that the "problem" was broken down into small manageable tasks and the aggregation of these tasks make up the working version of this application.

\section{Model Implementation}

State chart diagrams are used to model the different states the system will assume based on actions performed either on it (by clients) or by it. Figure 4 shows the state chart diagram for the system. A client can be registered or yet to register. In registration, if the client inputs invalid information, the client is taken back to the registration page. If registration is successful, the client logs in by typing the clients id and password. If data entered does not satisfy constraints imposed (wrong client id, password, and invalid character), the user is 
taken back to the login page. If login is successful, a buyer or seller can choose which action to perform. If a client tries to carry out an action without registering the system takes you back to log in page. On completion of a session, the client clicks on the Sign out link. The system abandons the session and goes back to the home page.

\subsection{User Interface}

Based on the class design for the system, different user interfaces are designed to enhance smooth communication between the different users of the system and the whole system. The different interfaces include:

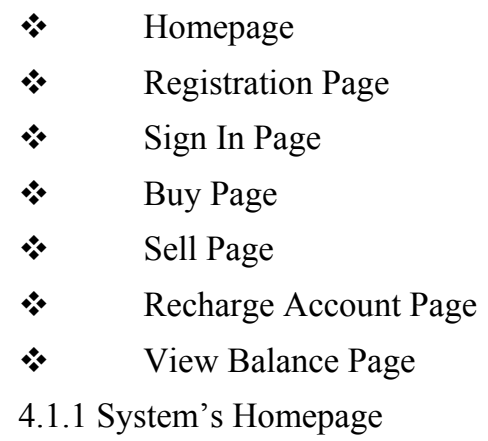

This screen is the first page that comes up once the site has being loaded. It displays all the list of product category that is books, electronics, cell phones etc and its corresponding images. From the list, the user can choose a category of interest; it provides links to other screen and it provides a link, which a buyer clicks, to check the clients account. The different product categories displaced are all from the populated database. The screenshot of the homepage is as shown in figure 5 .

\subsection{Expected Result}

The system will allow people to order for goods and buy these products by making use of recharge cards as in the case of mobile communications. People, especially the rural dwellers find it difficult to get credit cards which are the only means of buying and selling on the net. But, with the introduction of the use of recharge cards, people will find it easy to do on-line shopping.

\section{Conclusion}

There are problems associated with the existing shopping systems in Nigeria. Such problems include among others time-wasting process, inflexibility in time usage, need to physically go to the various shops to buy items, price discrimination by retailers, inability to meet enough buyers to sell their products and so on.

These problems have been addressed through the development of an Online Shopping Mart.

The EasyShop database contains working data for the entire activities carried out by the buyers and sellers. The product catalog, product category, client's registration records, buyers order records, delivery records, location records are a few of the records stored in the database. This database is protected by using a password that cannot easily be cracked. The application is also web based which makes Online Shopping Possible. On security, the measure implemented is the use of username and password which is well encrypted of data using secure socket protocol. Sensitive data is encrypted and is used to populate the database and it is decrypted when it is needed.

The EasyShop system will provide an easy to use and high security system for shopping online which will provide an ample opportunity for small scale sellers to compete with large-scale sellers. Also, there is capability to meet more buyers to sell their products to. The buyers also have increased flexibility in the use of their time while their data are protected.

\section{References}

Anyny (2009). E-commerce and Internet Industry in Nigeria. Retrieved on July 1,2009 at http://www.ecommerce-journal.com/articles/13989_e_commerce_and_internet_industry_in_Nigeria

Birkin M., Clarke, G. and Clarke, M. (2002). Retail Geography and Intelligent Network Planning, Chictster: Wiley.

Bakos Y. (1998). The Emerging Role of Electronic Marketplaces on the Internet. Communications of the ACM, $41(8)$, pp. $35-42$. 
Hoffman D.L., Novak T.P., \& Chatterjee, P. (1995). Commercial Scenarios for the Web: Opportunities and Challenges. Journal of Computed-Mediated Communication, Special issue on Electronic Commerce, Vol. 1 No 3.

Kotler P. (1997). Marketing Management: Analysis, Planning, Implementation and

Control. Prentice-Hall International, Inc., New Jersey. $9^{\text {th }}$ Edition.

Quelch, J.A., \& Klein L.R. (1996). The Internet and International Marketing. Sloan Management Review. $37(3)$, pp. $60-75$.

Rafter V. (1998). Reengineering Customer Service. The Industry Standard. Available at: http://www.thestandard.com/article/0,1902,1031,00.html. Accessed on 15 ${ }^{\text {th }}$ March, 2007.

Row H. (1997). Personal Best. Webmaster Magazine. p. 16.

Sterne J. (1995). World Wide Web Marketing. John Wiley \& Sons, Inc. New York. $3^{\text {rd }}$ Edition.

Table 1. Use Case Specification of Ordered Goods

\begin{tabular}{|l|l|}
\hline Name & Buy goods \\
\hline Actors & Buyer \\
\hline Pre-conditions & 1. The system displays the home page. \\
\hline Flow of events & $\begin{array}{l}\text { 1. The Use Case starts when user clicks on "buy" hyperlink using the mouse. } \\
\text { 2. The buyer logs on with username and password. } \\
\text { 3. The system reads buy criteria specified by sending the form. } \\
\text { 4. The buyer clicks on search option. } \\
\text { 5. The buyer sorts the retrieved results by selecting the desired option using the } \\
\text { mouse. } \\
\text { 6. The buyer clicks on the "buy" button to get full description of the product } \\
\text { and adds quantity to shopping cart. } \\
\text { 7. The buyer pays for the good. } \\
\text { 8. The system verifies account information. } \\
\text { 9. The system loads confirmation of order page. } \\
\text { 10. The buyer signs out. } \\
\text { 11. The use case terminates }\end{array}$ \\
\hline
\end{tabular}




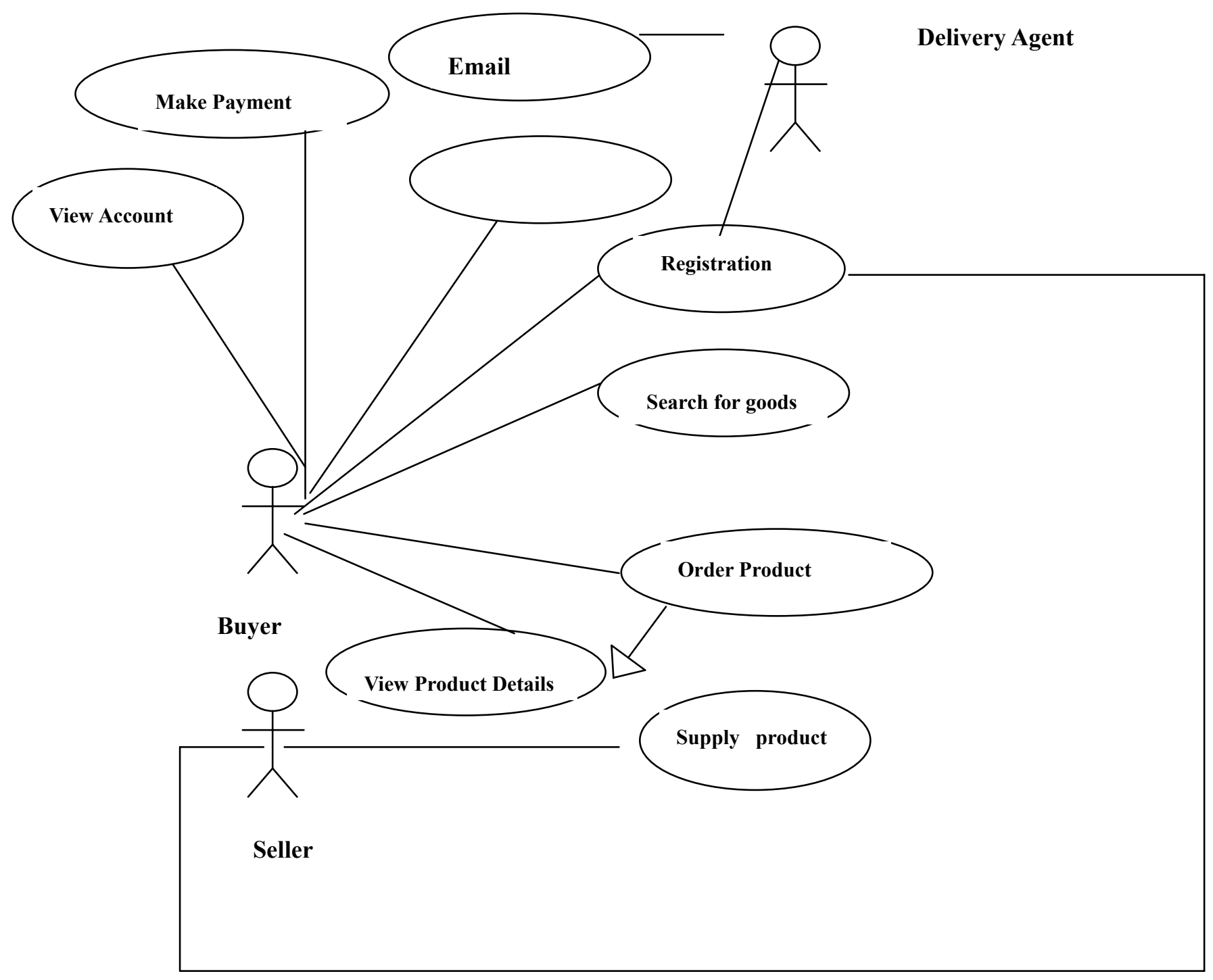

Figure 1. System Use Case Model 


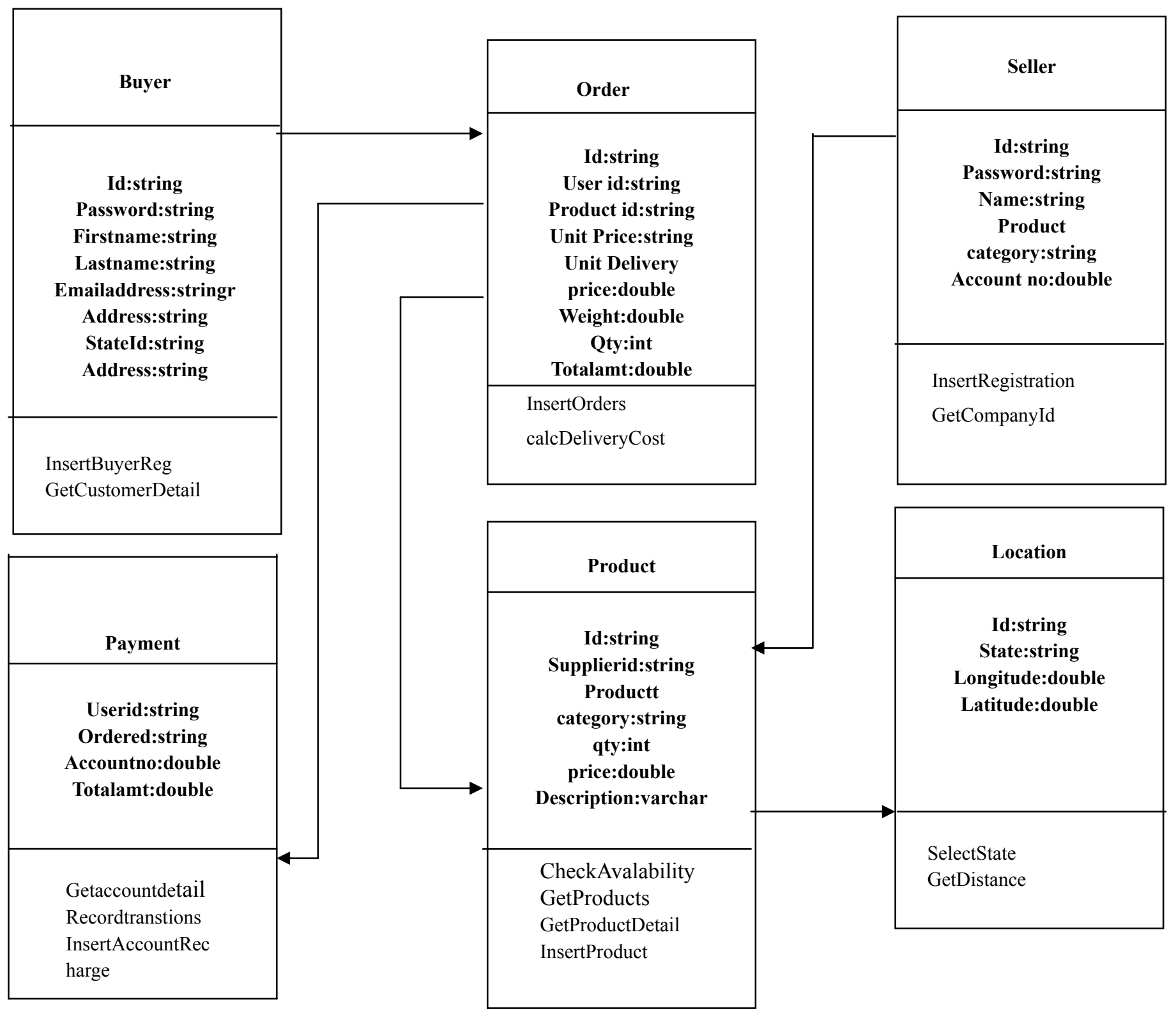

Figure 2. Class Diagram Analysis 


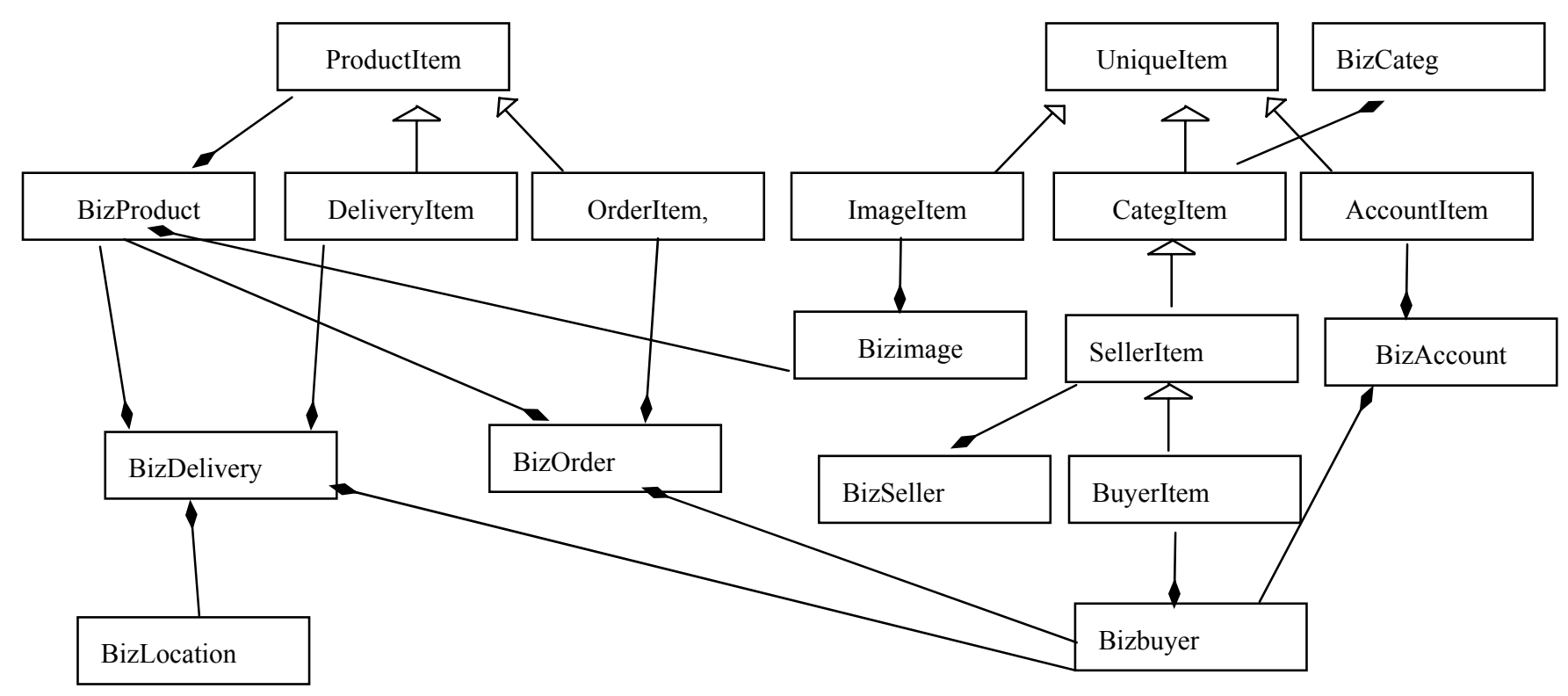

Figure 3. Design Class diagram for the system 


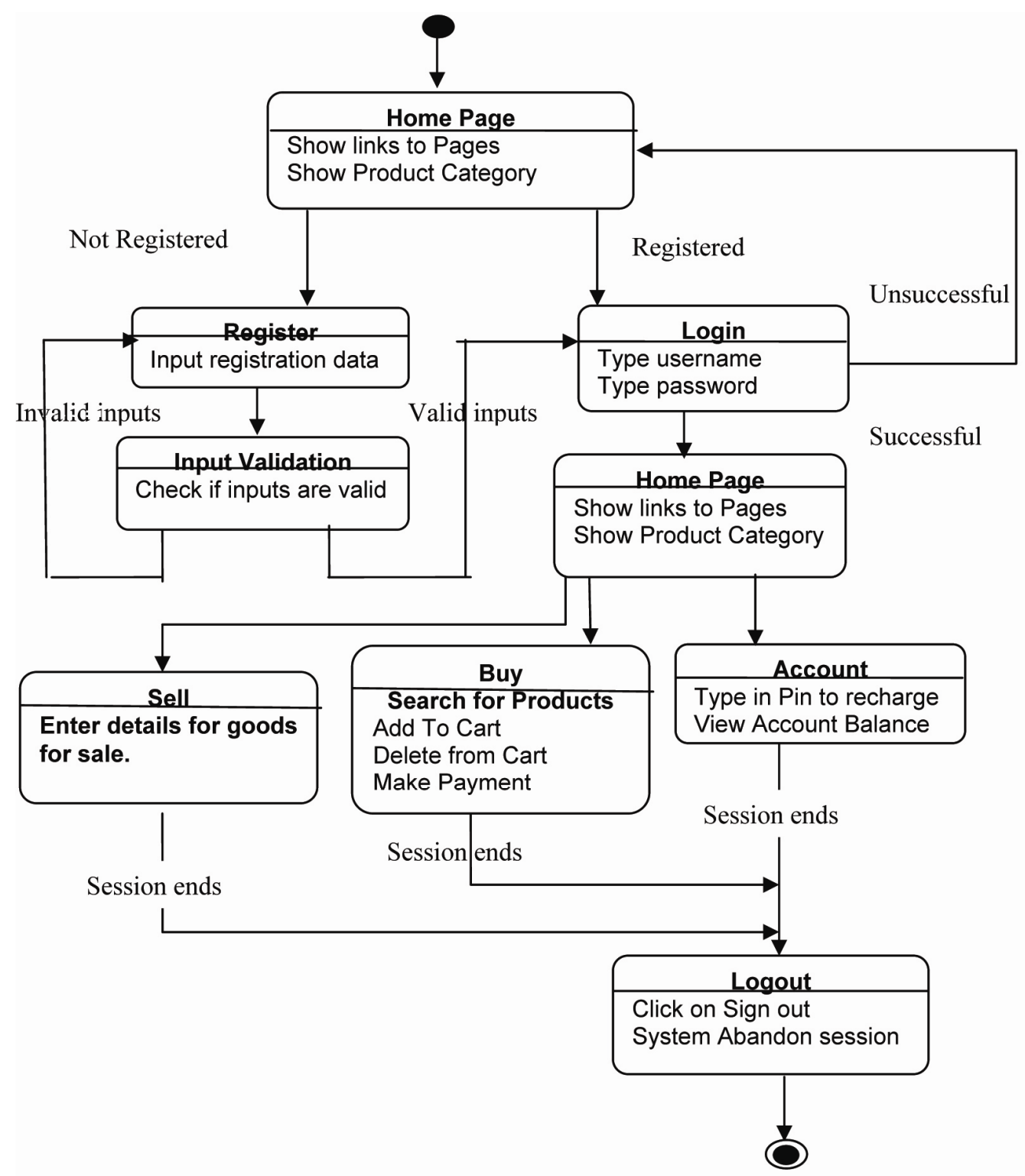

Figure 4. State Chart of the System 


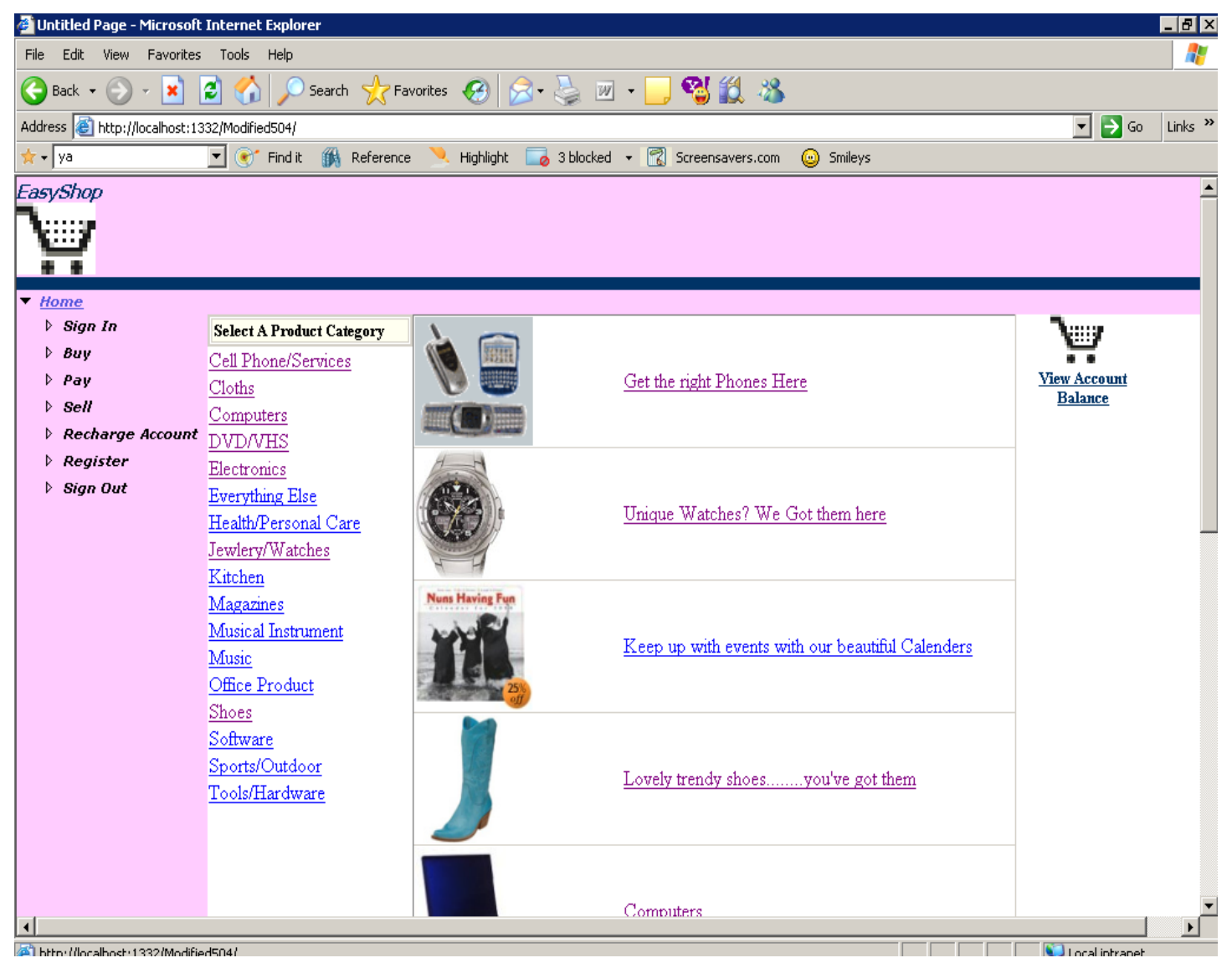

Figure 5. Homepage for the Proposed System 